\title{
Cancer and COVID-19: Currently in Race for the Title of "The Emperor of All Maladies!"
}

\begin{abstract}
Cancer has been the undisputed "Emperor of All Maladies" till now. The current COVID-19 pandemic has created havoc and seems to have displaced cancer from this notorious title. This narrative examines the facts and figures that have led to this succession.
\end{abstract}

Keywords: Cancer, COVID-19, global impact

The whole world is currently seized with the pandemic of COVID-19, with the outbreak spanning more than 200 countries. Physical suffering and a far greater mental anxiety are common to both the ailments, COVID-19 and cancer, with the former likely to supersede the status of cancer as "The Emperor of All Maladies."[1]

In fact, there are quite a few similarities between cancer and COVID-19. Both are associated with a significant degree of fear and phobia. They both result in a panic-like situation. The diagnosis of either is associated with the patients suffering sequentially through stages of disbelief, denial, and finally coping phenomena. The outcome of either illness is largely dependent on the stage (in cancer) and severity (in COVID-19). One is regarded as emerging either a winner (survivor) or a victim.

Can all the phobia and panic associated with COVID-19 be explained? The answer is both yes and no. Yes, because it is a new illness with so much yet unknown about it. We are still learning to diagnose it and deal with it. We are still not fully geared up to deal with the impending burden of the disease - in terms of hospital infrastructure, testing facilities, rapid diagnostic tests, workforce (in the form of doctors, nurses, and ancillary staff), and personal protective equipment. Furthermore, there is no definitive treatment based on large-scale clinical trials and preventive vaccine seems

This is an open access journal, and articles are distributed under the terms of the Creative Commons Attribution-NonCommercial-ShareAlike 4.0 License, which allows others to remix, tweak, and build upon the work non-commercially, as long as appropriate credit is given and the new creations are licensed under the identical terms.

For reprints contact: WKHLRPMedknow_reprints@wolterskluwer.com a bit far away at present. No, because we as doctors have earlier dealt with bigger challenges and overcome them. These challenges have been in the form of some earlier epidemics and pandemics (such as Spanish flu, bubonic plague, severe acute respiratory syndrome [SARS], Middle East respiratory syndrome, Nipah virus, and more recently Ebola). ${ }^{[2]}$ We have been able to successfully eradicate diseases such as plague and smallpox. We have found a cure for HIV and AIDS. Moreover, we have come a long way in our war against cancer. Cancer is thus no longer a death sentence that it used to be many decades ago. Some of the cancers are preventable as well by lifestyle modifications and also by prophylactic vaccines!

If numbers were a way to judge the differential need for panic, then here they are. As per the World Health Organization, there were a total of 18.1 million new cancer cases diagnosed in the year 2018, and 9.6 million succumbed to it. ${ }^{[3]}$ In the year 2020, in the USA alone, more than 1.8 million new cancer cases (excluding noninvasive cancers except that of the urinary bladder and basal and squamous cell carcinoma skin) are expected to be diagnosed. Furthermore, about 606,520 Americans are expected to die of cancer this year, a number surpassed only by heart disease. According to the GLOBOCAN 2018 data, there were about 1.16 million new cancer cases and 784,821 cancer deaths in India in 2018. ${ }^{[4]}$ Although cancer is known to humankind since antiquity, its incidence is increasing due to multiple

How to cite this article: Wadhwa J, Saigal A. Cancer and COVID-19: Currently in race for the title of "The emperor of all maladies!" Indian J Med Paediatr Oncol 2020;41:303-4.

\section{Jyoti Wadhwa ${ }^{1}$, Aniket Saigal'}

${ }^{1}$ Department of Medical Oncology, Medanta the Medicity Hospital, Gurugram, India, ${ }^{2}$ Department of Ecology and Evolutionary Biology, University of California Los Angeles, Los Angeles, USA

Submitted: 30-Apr-2020 Revised: 07-May-2020 Accepted: 12-May-2020 Published: 27-Jun-2020

Address for correspondence: Dr. Jyoti Wadhwa, Department of Medical Oncology, Medanta the Medicity Hospital, Sector 38, Gurugram - 122 001, Haryana, India.

E-mail: jyotiwadhwa@hotmail. com

Access this article online Website: www.ijmpo.org DOI: 10.4103/ijmpo.ijmpo_210_20 Quick Response Code:

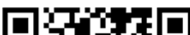

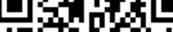
+4 4.

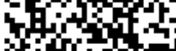

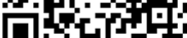


factors such as increased life expectancy, changing lifestyle, improved diagnostics, and cancer screening. ${ }^{[5,6]}$

The best available measure of control over an illness, be it cancer or COVID-19, would be the reduction in deaths due to it. For example, in the USA, the age-adjusted cancer death rate increased steadily, peaking in 1991 at 215 cancer deaths per 100,000 people, mainly because of the smoking epidemic. In 2017, the mortality rate dropped to $152 / 100,000$ due to reductions in smoking, and also improvements in early detection and treatment. The 5-year relative survival rate for all cancers combined has also increased significantly, from as low as $27 \%$ in the 1960 s to $70 \%$ currently. ${ }^{[7]}$

As of April 29, 2020, there are currently 3,138,895 confirmed cases and 218,010 deaths from the coronavirus (COVID-19) outbreak globally, with $1,035,765$ cases being in the USA alone in contrast to 33,050 confirmed COVID-19 cases in India till date. ${ }^{[8]} \mathrm{A}$ look at the number of deaths per hundred confirmed cases (observed case-fatality ratio) reveals that Belgium (15.1\%), the United Kingdom (13.5\%), Italy (13.5\%), and France $(13.9 \%)$ have the most deaths proportionally to their COVID-19 cases or population, not necessarily the most deaths overall. In the USA, the case-fatality rate of $5.7 \%$ has been reported ${ }^{[9]}$ In India, the same reported figure is at 3.2\%. Recently, deaths due to COVID-19 (almost 13,000) surpassed weekly deaths due to cancer (11,500 approximately) and heart disease (12,500 approximately), making COVID-19 the number one cause of mortality in the USA, surpassing both cancer and heart disease.

The economic burden of cancer is huge and progressively increasing. As per the IARC World Cancer Report of 2014, the total annual economic cost of cancer is estimated at approximately US $\$ 1.16$ trillion, which had been the highest for any disease. The COVID-19 pandemic has already adversely affected the global economy within this short span and its impact is likely to continue for a much longer period. The UN Department of Economic and Social Affairs has predicted about $1 \%$ shrinkage in the global economy due to the COVID-19 pandemic. Further, a fall in global trade to the tune of $13 \%-32 \%$ is predicted. The COVID-19 pandemic has adversely affected India's economy as well. In the period between April and June 2020, a gross value added loss of over $9 \%$ is estimated. ${ }^{[10]}$

Almost one-third of all cancers are preventable, another third curable, and for the remaining one-third, the outcome is variable depending on the nature and stage of the disease and the treatment offered. Patients with some cancers now live long with good quality of life, despite being in Stage 4 disease. Further, cancer is an uncommon cause of sudden tragic death. This is in stark contrast to the COVID-19 infection wherein one often does not know the source and is caught unprepared for the sudden downturn of the immunological response machinery with resultant respiratory and multiorgan failure. Due to its very high infectivity from person to person and transmission through fomites, COVID-19 pandemic has led to a huge societal impact. This pandemic has led to a new way of living with a big emphasis on personal hygiene and social distancing. The impact has been so huge that it led to a complete lockdown on a global scale with a need for isolation, contact tracing, and quarantine. Therefore, its control would entail a change in social behavior and global cooperation, which is in contrast to individualized treatment strategies for cancer. Even though efforts toward the development of anti-cancer vaccine have been unsuccessful till date, there is a ray of hope in the development of vaccine against SARS-CoV-2.

We are thus witnessing a new world, rather with a sad state of affairs globally, across continents. This new world is filled with human tragedy, with fearful people locked inside their four walls, often with inadequate supplies. So much so that COVID-19 has even snatched away the right to terminal care and also the right to die with dignity! It took humans decades of research in laboratories and clinics to win the war against some cancers. Before humankind could rejoice in its glory or plan to enhance its progress by taking a giant leap in time and space, the tiny, invisible, but very powerful and destructive novel coronavirus has wreaked havoc and definitely displaced cancer from the throne of "The Emperor of All Maladies!"

\section{Financial support and sponsorship}

Nil.

\section{Conflicts of interest}

There are no conflicts of interest.

\section{References}

1. Siddhartha M. The Emperor of All Maladies: A Biography of Cancer. New York: Scribner; 2010.

2. Available from: https:/www.history.com/topics/middle-ages/ pandemics-timeline. [Last accessed on 2020 Apr 29].

3. Available from: https:/www.who.int/health-topics/ cancer\#tab=tab_1. [Last accessed on 2020 Apr 29].

4. Available from: https://gco.iarc.fr/today/data/factsheets/ populations/356-india-fact-sh eets.pdf. [Last accessed on 2020 Apr 29].

5. Smith RD, Mallath MK. History of the growing burden of cancer in India: From antiquity to the $21^{\text {st }}$ century. J Glob Oncol 2019;5:1-15.

6. Bray F, Ferlay J, Soerjomataram I, Siegel RL, Torre LA, Jemal A. Global cancer statistics 2018: GLOBOCAN estimates of incidence and mortality worldwide for 36 cancers in 185 countries. CA Cancer J Clin 2018;68:394-424.

7. American Cancer Society. Cancer Facts \& Figures 2019. Atlanta: American Cancer Society; 2019.

8. Available from:https://www.worldometers.info/corona virus/\#countries. [Last accessed on 2020 Apr 29].

9. Available from: http://Coronavirus.jhu.edu/data/mortality. [Last updated on 2020 Apr 25].

10. Impact of the Coronavirus Pandemic on the Global Economy-Statistics \& Facts; Published in April, 2020. Available from: https://www.statista.com/topics/6139/covid-19-impacton-the-global-economy/. [Last accessed on 2020 Apr 29]. 